\title{
A semântica do passado
}

\author{
Nelson Gonçalves Gomes \\ Professor no Departamento de Filosofia \\ Universidade de Brasília - UnB \\ nelson.gomes235@gmail.com
}

Como citar este artigo: GOMES, N. G.. "A semântica do passado", Intelligere, Revista de História Intelectual, nº10, pp. 191-205. 2020. Disponível em < http://revistas.usp.br/revistaintelligere>. Acesso em dd/mm/aaaa-

Resumo: Este artigo apresenta a linguagem do passado, no contexto do antirrealismo de Michael Dummett. Ao final, de modo breve, o papel dos condicionais contrafáticos é enfatizado.

Palavras-chave: Intuicionismo, antirrealismo, semântica do passado, condicionais contrafácticos.

\section{The semantics of the past}

Abstract: This article is about the language of the past tense within the frame of Michael Dummett's antirealism. The role of counterfactual conditionals is briefly emphasized.

\footnotetext{
${ }^{1}$ Professor titular de Filosofia na Universidade de Brasília (1976-2013). Professor colaborador do Programa de Pós-Graduação em Filosofia na UnB desde 2015. PhD pela Universidade de Munique (1975). Foi professor na Faculdade Católica de Filosofia de Santos (1967-69) e na Universidade de São Paulo (Ribeirão Preto, 1991-92). Realizou projetos de pós-doutorado em Munique, Londres, Oxford e Jerusalém. Áreas de especialização: (1) lógica, (2) filosofia analítica (neopositivismo) e (3) metaética (com ênfase sobre as relações entre lógica e discurso moral.Contato: nelson.gomes235@gmail.com

Lattes:http://lattes.cnpq.br/2826537572017302
} 
Keywords: Intuitionism, antirealism, semantics of the past tense, counterfactual conditionals.

A Amado Luiz Cervo, com viva lembrança da nossa amizade de quase meio século!

"The past is a foreign country; they do things differently there." L. P. Hartley The Go-Between (1953)

\section{A linguagem do passado}

Em muitos contextos e de diversas formas, o passado foi objeto de reflexão ao longo da história da filosofia. Contemporaneamente, de modo muito particular e elaborado, o filósofo britânico Michael Dummett (19252011) tratou desse tema, numa série de conferências por ele pronunciadas na Universidade Columbia. Essas palestras foram publicadas num pequeno livro de 2004: Truth and the Past. (Dummett, 2004) O que torna bastante original a abordagem desse filósofo quanto ao passado é a sua perspectiva linguística. Dummett foi um significativo filósofo da linguagem, particularmente concentrado na elucidação do conceito de significado. A concepção de Dummett sobre o passado, em grande parte, desenvolve-se como teoria sobre a linguagem a respeito do passado, que assume a forma de uma posição peculiar chamada de justificacionismo. Este último, por sua vez, apoia-se numa formulação da lógica e da matemática contemporâneas conhecida como intuicionismo. Dummett consegue trazer para a filosofia uma série de elaborações teóricas que pareciam estar restritas a certas tomadas de posição no âmbito dos fundamentos da matemática.

No presente artigo, a mencionada teoria de Dummett será delineada, também a partir de um outro pequeno livro, por ele primeiramente publicado em tradução italiana. (Dummett, 2010 (2001)) Em seguida, algumas consequências desse tipo de pensamento serão aqui examinadas, de modo particular, no que diz respeito à história enquanto disciplina voltada ao estudo do passado. Para melhor entendimento dessa abordagem, vale a retomada de alguns conceitos preliminares, como realismo, antirrealismo, proposição e semântica. 
No uso cotidiano da expressão, uma pessoa realista é alguém capaz de lidar com fatos de modo objetivo, sem ilusões ou ingenuidades. Caso contrário, ela será chamada de irrealista. Em certos discursos filosóficos, realista é quem, pretensamente, cinge-se a falar sobre o mundo tal como ele é, sob pena de ser antirrealista. No contexto deste trabalho, as expressões "realismo" (ou "realista"), assim como "antirrealismo" (ou "antirrealista") são tomadas em acepções bem diferentes e especiais. Nestas presentes linhas, "realismo" ou "antirrealismo" designam perspectivas filosóficas voltadas para o entendimento de certos tipos de proposições.

Uma proposição, por sua vez, é aquilo que um enunciado declarativo expressa. Frases como "A neve é branca", "Schnee ist weiss" e "Snow is white" são diferentes entre si, pois pertencem a idiomas distintos. Não obstante, todas elas expressam a mesma proposição, pois as três dizem que a neve é branca. Na tradição filosófica mais conhecida, Verdade ou Falsidade são os valores que podem ser atribuídos a uma proposição. Semântica é a dimensão da linguagem que tem a ver com significado e verdade.

\section{Intuicionismo}

A concepção do seja a aritmética, tal como foi desenvolvida por Gottlob Frege (1848-1925), ao final do século XIX e princípio do XX, fundamenta-se em certas teses tradicionais da lógica, tomadas como evidentes. Duas dessas teses merecem destaque: (1) Princípio da Bivalência: Uma proposição é verdadeira ou falsa; (2) Princípio do Terceiro Excluído (Tertium Non Datur): Dadas uma proposição e a sua negação, uma delas é verdadeira e a outra falsa. Em geral, tomando-se p como uma proposição qualquer, o Princípio do Terceiro Excluído é resumido na expressão "p ou não-p", que significa: $\mathrm{p}$ é verdadeira ou p é falsa. Nos termos de Frege, a aritmética é composta por proposições verdadeiras, que refletem uma ordem relativa a objetos ideais, ordem essa irredutível às nossas experiências. Matemáticos e filósofos, como Bertrand Russell (1872-1970), dentre outros, seguem tal concepção, embora de forma matizada e mais geral, estendendo-a a toda a matemática e não apenas à aritmética. Essa linha de pensamento é chamada de matemática clássica. 
No referido período, a concepção clássica foi objeto de contestação por parte de alguns matemáticos insatisfeitos com a acentuada idealização nela envolvida. Um dentre eles foi o holandês L.E.J. Brouwer (1881-1966), prócer da referida corrente de pensamento matemático chamada intuicionismo. Nessa linha de reflexão, a tarefa central do matemático resume-se em elaborar provas (ou demonstrações) para proposições da sua área, ou, então, em encontrar refutações que as eliminem. Quando ele tem êxito no seu trabalho e consegue provar uma determinada proposição p, então está habilitado a dizer que p é verdadeira. Se, ao contrário, consegue refutar $\mathrm{p}$, ele dirá que p é falsa. Mas enquanto p não for provada ou refutada, ela será mera hipótese, em si mesma externa ao repertório do discurso matemático. Tal repertório cresce na medida na qual novas demonstrações ou refutações são elaboradas, de maneira que a matemática intuicionista está sempre bem delimitada, pois não inclui hipóteses.

Neste contexto, um exemplo sugestivo é a assim chamada Conjectura de Goldbach: "Todo número par, maior do que 2, é igual à soma de dois números primos". Sabidamente, $4=2+2 ; 6=3+3 ; 8=5+3$, e assim por diante. Porém, tal enumeração de exemplos não é uma demonstração. Existe uma prova para essa conjectura? Não, até hoje tal prova inexiste. Existe para ela alguma refutação? Não, tampouco existe tal refutação. Pode-se dizer que a conjectura é verdadeira ou falsa? Não, consoante o intuicionismo. Poder-se-ia afirmar tal coisa apenas se, respectivamente, ela fora demonstrada ou refutada. Como esse não é o caso, os princípios da Bivalência e do Terceiro Excluído não podem ser aí aplicados. Tal recusa a uma aplicação geral desses dois princípios tradicionais é constitutiva da citada linha de pensamento. Mais ainda: não se pode dizer que, nesse caso, a Conjectura de Goldbach tenha um terceiro valor, talvez, o Indeterminado. A conjectura, simplesmente, permanece fora do discurso intuicionista, até que, quiçá, alguém consiga demonstrá-la ou refutá-la.

O intuicionismo recusa a ideia de que o trabalho do matemático seria algo assim como navegar entre entidades ideais, capturadas por meio dos olhos da inteligência. Essa linha vê em tal trabalho uma atividade de construção criativa, cujo resultado possa ser efetivamente exibido. Como exemplo, sejam as seguintes definições:

(D1) k é o maior número primo tal que k-1 também é primo, ou, $k=1$, se tal número não existir. 
(D2) l é o maior número primo, tal que l-2 também é primo, ou, l=1, se tal número não existir.

A definição (D1) é admissível, em termos intuicionistas, pois k pode ser calculado e efetivamente exibido: k=3. A definição (D2), porém, é admissível apenas para a matemática clássica, mas é recusada em termos intuicionistas. O raciocínio clássico relativo a (D2) seria o seguinte: a sequência de pares de números primos do tipo (1, 1-2), ou seja, $(5,3) ;(7,5) ;(13,11) ; . .$. , é finita ou é infinita. Se for finita, o primeiro elemento do último par será o número procurado. Se for infinita, não existirá tal número e $1=1$. Nesse raciocínio, o Terceiro Excluído tem papel crucial (a sequência é finita ou infinita). Entretanto, nele, o número referido não é construído e exibido, mas apenas afirmado como existente. (Heyting, 1971 (1956), p. 2) Por essa razão, (D2) é aceito na matemática clássica, mas é intuicionisticamente inadmissível.

De modo geral, na versão de Brouwer, o intuicionismo enfatiza a tese de que entidades matemáticas são livres criações da mente humana, produzidas por meio de construções mentais. Elas não são entidades ideais platonicamente pré-existentes, descobertas pela inteligência do homem. A matemática não é produto de descobertas, mas sim de invenções.

No século XVIII, Kant já afirmara que o conceito de número se realiza "por meio do acréscimo sucessivo de unidades no tempo". (Kant 1968 (1783): $\$ 10,18-21)$ Nessa linha, o processo trivial de contagem, com os dedos da mão, por exemplo, pode ser entendido como a base intuitiva a partir da qual números inteiros positivos são concebidos: 1, 2, 3, 4, 5, ... O conhecido exemplo de Kant, $7+5=12$, reduz-se ao seguinte, em termos de adições sucessivas: $7+1+1+1+1+1=12$. A contagem sempre pode prosseguir, ilimitadamente, mas ela nunca estará completa. Assim, nos termos do intuicionismo, o infinito disponível para o matemático é sempre uma construção potencial, incompleta, em aberto, bem diferente do infinito tal como concebido pela matemática clássica, o assim chamado infinito real (ou atual), que é entendido como completo, acabado, fechado.

No contexto dessa crítica à matemática clássica, formou-se a matemática intuicionista, que rejeita os princípios de Bivalência e Terceiro Excluído, assim como o recurso ao infinito atual. Na verdade, a matemática intuicionista é uma parte da matemática clássica, pois tudo o que ela 
desenvolve tem igualmente valor clássico, embora não se dê a direção inversa. A matemática intuicionista é construtiva e, portanto, mais rigorosa. Nela, figuradamente, uma demonstração é como uma peça de tricô: dá-se um ponto inicial e, em seguida, sucessivos outros pontos são dados, consoante regras estritas. Uma tal peça é uma construção.

Brouwer contribuiu para o delineamento do intuicionismo, mas a lógica e a matemática dessa linha de pensamento foram desenvolvidas em minudências por um discípulo seu, o holandês Arend Heyting (1898-1980), cujas formulações nem sempre foram aplaudidas pelo mestre. (A. Heyting, $1971(1956))$

\section{Crítica à semântica das condições de verdade}

O que é a matéria escura? A física ainda não dispõe de uma resposta para tal pergunta. Suponha-se, porém, que alguém arrisque uma opinião e diga que tal matéria é composta de XYZ. Num tal caso, a priori, o pensador realista, dirá que essa opinião é verdadeira ou falsa (Princípio da Bivalência). Ele dirá, também a priori, que, dadas tal opinião e sua negação, uma dentre as duas será verdadeira e a outra falsa (Princípio do Terceiro Excluído).

A intuição do realista, segundo Dummett, deixa-se expressar na lógica clássica por meio da semântica das condições de verdade, na qual uma série de itens são definidos, de maneira a estabelecer as condições sob as quais os dois clássicos valores de verdade são atribuídos a enunciados de uma certa linguagem (a rigor: às proposições que eles expressam). A formulação dessa semântica dá-se por meio dos assim chamados T-enunciados, do quais o seguinte é um exemplo simplificado:

'A matéria escura é composta de XYZ' é uma enunciação verdadeira se, e somente se, a matéria escura é composta de XYZ.

$\mathrm{Na}$ sua crítica ao tipo de semântica ora delineada, Dummett faz uma distinção relativa ao conteúdo de um enunciado, ao diferenciar o assertórico do ingrediente. Quando o falante ouve um enunciado e o toma como verdadeiro, aquilo que ele considera como sendo real constitui o conteúdo assertórico do que lhe foi dito. Ao ser informado de que está chovendo e aceitar tal afirmação, o falante dá crédito a esse conteúdo, que é assertórico. O conteúdo 
ingrediente de um enunciado, por sua vez, é a contribuição que ele dá ao conteúdo assertórico de um enunciado mais complexo do qual ele seja um subenunciado.

Considere-se a seguinte situação. Alguém fala com um amigo ao telefone e ouve o seguinte: "Está chovendo aqui". Se o amigo disser "Está chovendo onde eu estou", o ouvinte receberá a mesma informação, pois esses dois enunciados têm idêntico conteúdo assertórico. Porém, se a expressão "sempre" lhes for acrescentada, enunciados mais complexos serão formados: “Sempre está chovendo aqui”, "Sempre está chovendo onde eu estou”. Estas duas últimas asserções têm conteúdos ingredientes muito diferentes entre si. A primeira diz que sempre chove em certo lugar, enquanto a segunda afirma que a chuva acompanha o interlocutor, onde quer que ele esteja. (Dummett, 2004, p.32-3)

Ao aplicar essas diferenças entre conteúdos ao exemplo citado, logo se percebe um problema: o T-enunciado é complexo e nele há duas ocorrências da asserção sobre a matéria escura, ambas como sub-enunciados, uma delas com aspas, a outra sem. O T-enunciado tem o seu próprio conteúdo assertórico, para o qual os sub-enunciados contribuem por meio dos respectivos conteúdos ingredientes. Mas estes últimos são diferentes entre si.

Dummett entende que a semântica das condições de verdade, ao pressupor Bivalência e Terceiro Excluído, constitui-se na base lógica do assim chamado realismo, com a sua pretensão de estabelecer relações entre enunciado e realidade. Tal semântica é incompatível com o justificacionismo.

Outras críticas são também arroladas por Dummett contra a semântica das condições de verdade. Ele objeta que cabe ao filósofo investigar significado e verdade em paralelo, e não significado como derivação de verdade. Nessa linha, Dummett seleciona certas enunciações cujos significados o falante entende, mas sem poder discernir para elas as respectivas condições de verdade ou falsidade. É comum que as pessoas pensem sobre suas vidas pregressas em termos de asserções condicionais do tipo "Se eu tivesse aceitado aquele emprego, hoje a minha vida seria melhor". Tais formulações, entretanto, não se deixam decidir de maneira efetiva. (Dummett, 2010 (2001), p. 132)

Uma refinada objeção pode ser feita contra a semântica das condições de verdade. Suponha-se que o falante entenda certa enunciação, mas sem saber 
como decidir se ela é verdadeira ou falsa. Nesse caso, restaria o recurso à suposição de que ele teria alguma habilidade interior de resolver tal problema. Assim sendo, porém, a tradicional filosofia analítica da linguagem seria incoerente. Isso porque, desde Frege, ela se propõe a explicar o funcionamento do pensamento por meio de um entendimento do mecanismo da linguagem. Mas, se o mencionado recurso for levado em consideração, o mecanismo da linguagem será explicado por meio de habilidades do pensamento, o que forma um círculo vicioso. (Dummett, 2010 (2001), p. 134-5)

Os argumentos ora resumidos levam a versão do justificacionismo representada por Dummett a rejeitar a semântica das condições de verdade e o realismo que nela se baseia.

\section{O justificacionismo antirrealista}

A lógica intuicionista, apesar de todo o interesse que desperta, tem cunho matemático estrito e não pode, simplesmente, ser transposta para fora desse domínio. Quem fala sobre a natureza, constelações, mares, cordilheiras, animais, sociedades, pessoas e outros temas não terá condições de sobre eles desenvolver demonstrações tal como as constrói o matemático construtivista. Há uma diferença importante entre questões lógico-matemáticas e questões de outras áreas: quando as condições para a prova de uma proposição estão bem estabelecidas, elas assim permanecem; fora da lógica e da matemática, entretanto, condições que dariam sustentação a certo tipo de discurso podem sofrer mudanças significativas. O que decide a solução de um problema empírico está sujeito a desaparecer ou a modificar-se. Documentos de interesse histórico, por exemplo, podem deixar de existir sem deixar rastro, o que prejudica o respectivo conhecimento empírico. (Dummett, 2004, p. 42)

Reflexões como essas mostram a necessidade de uma ampla abordagem sobre a linguagem, que sempre deve ser examinada sob o ponto de vista de uso. Uma criança pequena aprende, paulatinamente, a empregar a linguagem. Ela aprende com o adulto, cuja fala, ao início, ela imita: na presença de um cão, a criança aprenderá a pronunciar sílabas simples, que soam como o ladrado desse animal. Ao começo, o que o adulto observa serve para ensinar expressões à criança, mas ela progride quando aprende a empregar enunciações 
dos adultos para referir-se às suas próprias observações infantis. Pouco a pouco, a criança aprende a aceitar o testemunho alheio, a incorporar o que outras pessoas dizem, o que é crucial, pois a linguagem une todos os indivíduos à sociedade. A linguagem inclui até mesmo os mortos no seu domínio, pois algo do que eles enunciaram permanece na rede linguística que atua entre os vivos. É a linguagem que leva o conhecimento a estender-se continuamente por todos os ângulos da vida social. (Dummett, 2004, p. 47-55)

De modo particular, a criança aprende a falar sobre o espaço no qual está, em certas circunstâncias. Em seguida, aprende a falar sobre espaços contíguos ao primeiro e, depois, sobre espaços mais remotos. Simultaneamente, ela aprende a falar sobre o tempo, o que inclui o presente, o futuro e o passado. Ela aprende o que significa dizer que certo evento (uma festa, por exemplo) esteja acontecendo em certo lugar, mesmo se for distante. A criança aprende, igualmente, a verificar se tal evento ocorre, o que implica ir até o lugar e confrontar-se com o fato relevante. (Dummett, 2004, ibidem)

Essas considerações sugerem um resultado central: ao aprender a linguagem, a criança aprende a justificar suas enunciações, a explicar por que ela diz isso ou aquilo. Ao longo do processo de aprendizado, a criança e o jovem são constantemente chamados a apresentar razões para aquilo que dizem. Criança e jovem aprendem a tratar enunciações de outros como se fossem suas, num contínuo recurso ao testemunho. Por isso mesmo, Dummett dá o nome de justificacionismo à sua concepção de linguagem, que deve ser muito mais abrangente do que o intuicionismo no qual ela se inspira. (Dummett, 2010 (2001), p. 136).

Nas suas múltiplas interações com as demais pessoas, o indivíduo não tem como demonstrar de modo cogente o que diz sobre objetos presentes no tempo e no espaço, mas ele tem como justificar as enunciações que assere, mesmo porque essa é uma prática corriqueira e constitutiva da linguagem. Demonstrações (ou provas) são ubíquas na lógica e na matemática e apenas nelas, enquanto que toda a linguagem embebe-se por justificações.

Ainda em analogia à concepção intuicionista, define-se o conceito de verdade, no justificacionismo: uma proposição é verdadeira se existe um meio (método ou processo), em princípio, efetivo, de justificá-la. (Dummett, 2010 
(2001), ibidem) Se tal meio não existe, em termos efetivos, a proposição será falsa.

Se alguém vai a certo lugar porque lhe disseram que naquele espaço estaria acontecendo um jogo e, efetivamente, lá encontra a prática relevante, ele dirá que recebeu uma informação verdadeira. Nesse caso, o indivíduo tem na sua verificação um processo efetivo que justifica a informação recebida. Se ele encontra o espaço vazio, dirá que foi mal informado. Em princípio, qualquer outra pessoa poderá realizar esse tipo de procedimento, pois a verificação não é atividade individual, mas sim coletiva. (Dummett, 2004, p. 52)

Ao estabelecer a priori que qualquer proposição p é verdadeira ou falsa, o Princípio da Bivalência define valores de verdade para uma infinidade de proposições, mas sem que elas tenham sido examinadas, justificadas ou recusadas por qualquer falante. Neste ponto, vale a analogia com o intuicionismo: o matemático só atribui verdade ou falsidade a uma proposição depois de, correspondentemente, prová-la ou refutá-la. Diante de inúmeras proposições que não se examinou, nenhum falante terá condições legítimas de atribuir-lhes valores de verdade. Por essa razão, o justificacionismo rejeita o Princípio da Bivalência. De modo análogo, ele rejeita, igualmente, o Princípio do Terceiro Excluído: se uma proposição como a Conjectura de Goldbach não foi provada nem refutada, não há por quê, a priori, contrapô-la à sua negação e dizer que uma dentre as duas é verdadeira e a outra falsa.

Neste contexto, destaca-se um caso bizarro. Suponha-se a seguinte enunciação "Laertes era canhoto", na qual Laertes é o conhecido personagem da peça Hamlet, de Shakespeare. Dummett observa que até o célebre poeta não teria como justificar ou recusar a proposição aí envolvida, mesmo porque não há verdade a respeito do assunto. Mas, como os conceitos de verdade e falsidade ligam a semântica à metafísica, pode-se sugerir que haja vácuos na realidade, embora não se os possa, efetivamente, localizar. Proposições problemáticas como essa citada permanecem em suspenso. (Dummett, 2004, p. 63-4)

\section{Justificacionismo mitigado}

Suponha-se que os enunciados mais simples da linguagem sejam decidíveis, no sentido de o falante sempre dispor de algum meio para atribuir 
verdade ou falsidade àquilo que eles expressam. Por exemplo, se o enunciado "Está chovendo" for simples, bastará ao falante estender a mão para fora da sua janela de modo a saber se a frase manifesta ou não a verdade. Mas, sob tal suposição, por que o falante não tem como decidir sobre a verdade ou falsidade de proposições expressas por determinados enunciados complexos? Em resposta a essa questão, Dummett remete a linhas que escrevera anteriormente, nas quais indicara três fontes de indecidibilidade: a quantificação sobre um domínio ilimitado (por exemplo: "Nunca a Conjectura de Goldbach será demonstrada”), o condicional contrafáctico (“Se eu fosse tu, estudaria mais para o concurso") e as proposições sobre o passado ("Cabral descobriu o Brasil"). O último grupo foi objeto de sua particular atenção.

Dummett pergunta como o justificacionismo antirrealista estrito poderia entender proposições sobre o passado e chegou a algumas conclusões centrais. Primeiramente, essa versão assume a tese de que o passado se encerrou de modo radical, de que ele não mais existe. Portanto, tudo o que resta do passado está nos dias de hoje: memórias, documentos, relatos, obras de arte e outros traços residuais. Consequentemente, proposições justificadas e formuladas hoje sobre o passado não são verdadeiras ou falsas em virtude do próprio passado, mas sim em virtude de tais resíduos ora presentes. Em outras palavras, como apenas o que existe pode dar verdade ou falsidade a uma proposição e sendo que só o presente existe, proposições hodiernas sobre o passado, eventualmente justificadas, serão verdadeiras ou falsas tão somente em virtude de resíduos hoje remanescentes e não em virtude do próprio passado. A rigor, não se fala sobre o passado enquanto tal, mas sempre sobre suas relíquias contemporaneamente manifestas. (Dummett, 2004, p. 66-7)

Dummett reconhece que tal teoria é consistente, mas entende que é inaceitável, descrevendo-a como repugnante. Embora permaneça fiel às concepções centrais do justificacionismo antirrealista, Dummett prefere dele se afastar no que tange ao entendimento do passado e proposições a seu respeito. Ele não renuncia à lógica intuicionista, à crítica aos princípios de Bivalência e Terceiro Excluído, e ao esquema geral do justificacionismo, mas reconhece certos limites do construtivismo, quando aplicado a questões empíricas. Isso porque, num argumento construtivo empírico, a suposta verificabilidade das 
premissas não necessariamente se transmite às respectivas conclusões. (Dummett, 2004, p. 43-6)

Que tipo de justificacionismo parcialmente mais liberal pode ser delineado, de modo a que daí resulte um entendimento tratável sobre proposições voltadas ao passado? Ao descrever o aprendizado da linguagem por parte de uma criança, Dummett enfatiza que ela aprende a falar sobre o lugar no qual está, sobre lugares adjacentes e remotos, assim como sobre eventos que ocorram em tais espaços que, ao menos em princípio, ela pode percorrer. De maneira muito direta, a criança aprende a verificar o que acontece em tais lugares. Mas, em se tratando do passado, ninguém pode visitar tais ambientes, pois ele não mais é acessível. Nesse caso, como verificar o que lá ocorreu?

$\mathrm{Na}$ sua resposta, primeiramente, Dummett admite que o passado tem alguma forma de existência, sobre a qual proposições podem ser justificadas e receber valores de verdade, verdadeiro ou falso. Esse é um passo inicial que representa uma importante aproximação relativamente à metafísica realista, segundo a qual objetos, fatos, processos, existiram (e existem, de alguma forma) independentemente da avaliação contemporânea. Ao falar sobre o passado, ninguém tem a liberdade do matemático intuicionista com suas construções criativas. O passado está delimitado pelo que aconteceu (e acontece, de alguma forma). Uma vez colocada tal tese metafísica, Dummett articula-a com a sua concepção filosófica: A linguagem é aprendida pela criança numa série de passos, o seu uso implica constantes verificações e justificações, ela funciona como teia universal que possibilita a comunicação de conhecimento em todos os níveis e entre todas as gerações.

Considere-se o exemplo da carta ao rei de Portugal sobre o achamento do Brasil, escrita da então Ilha de Vera Cruz, com data do dia 1o de maio de 1500 e redação de Pero Vaz de Caminha (1450-1500), o escrivão de Calicute. Caminha estava presente a tudo aquilo que descreveu: a vista do Monte Pascoal, a aproximação da terra, a paisagem, os densos arvoredos, as águas abundantes, os índios nus, suas pinturas corporais, seus alimentos, seu comportamento frente aos recém-chegados, a primeira missa e outros pormenores. A carta é relato de um observador atento e minucioso, que estava presente quando e onde as coisas aconteceram. Ela contém elementos que 
Caminha e outros nela citados verificaram. Em particular, a carta destaca Pedro Álvares Cabral (1467-1520), o descobridor da nova terra. Ao assinar o documento, o escrivão firmou o seu testemunho frente ao rei.

Consta que, no dia 17 de dezembro de 1500, Caminha sucumbiu em combate contra atacantes muçulmanos, em Calicute. Mas, como observa Dummett, a morte é um item que não rouba de ninguém a condição de observador ou de informante. $\mathrm{O}$ morto continua a ser membro da comunidade, mesmo se as suas mensagens venham a ser obliteradas. (Dummett 2004, p. 68) As narrativas de um contemporâneo são examinadas, discutidas, aceitas ou rejeitadas, sendo que o mesmo ocorre com respeito às mensagens deixadas pelos mortos. A linguagem faz com que todos os homens sejam contemporâneos.

O exemplo da carta de Caminha ilustra o tipo de teoria da linguagem e de justificacionismo mitigado que Dummett adota. A linguagem é a teia que percorre toda a humanidade, hoje e em tempos de antanho. Como todos os humanos, Caminha aprendeu a usá-la, a fazer verificações e justificações, a aceitar e a dar testemunhos, sempre num contexto coletivo. Os enunciados por ele escritos puderam ser justificados e tomados como verdadeiros frente àqueles fatos de 1500 que, de alguma maneira, ainda estão presentes. É no discurso sobre o passado que a inspiração do intuicionismo construtivista encontra o seu limite e uma forma mitigada de realismo é admitida. A matemática intuicionista é invenção, não descoberta. A história é descoberta, não invenção.

Como reza a frase de Hartley em epígrafe neste artigo, o passado é uma terra estrangeira, na qual as coisas são feitas de modo diferente. Ninguém mais pode visitá-la, mas há mensagens que de lá chegam aos tempos de hoje. Por meio delas, essa terra estrangeira torna-se conhecida daqueles que até lá não mais viajam. Pero Vaz de Caminha é um contemporâneo que habita num reino ora inacessível.

\section{Condicionais contrafácticos}

Dentre os três tipos de enunciados que Dummett menciona como fontes de indecidibilidade na linguagem, os condicionais contrafácticos também se destacam por apresentar algum interesse para a história, disciplina 
voltada para o estudo do passado. Tais condicionais sempre têm um antecedente falso. Eles são hipóteses relativas ao que não acontece.

Ao falar sobre o passado, há quem evite os condicionais contrafácticos, justamente por neles reconhecer proposições hipotéticas cuja verdade ou falsidade não tem como ser decidida. Numa discussão informal, alguém pode dizer: "Se Napoleão tivesse vencido a batalha de Waterloo, a França seria hoje a primeira potência da Europa". Faz sentido dizer que tal proposição seria passível de justificação efetiva? Aparentemente, não, porquanto a eventual verdade do consequente dessa hipótese deveria sintetizar uma enorme sequência de processos e de eventos reais ou meramente possíveis, sequência essa que só seria desenvolvida no plano da imaginação do falante.

Porém, nem todos os condicionais contrafácticos são tão distantes de algum processo de justificação. Considere-se o seguinte exemplo: "Se Bartolomé Mitre não tivesse apoiado o Império do Brasil contra Solano López, o país não teria conseguido expulsar os paraguaios que invadiram a província do Mato Grosso". Essa proposição parece dotada de considerável plausibilidade, de vez que, nas condições daquela época, sem poder navegar pelos rios da Prata e Paraná, o Exército Imperial teria de vencer um enorme percurso a pé, em condições muito desfavoráveis, desde o litoral brasileiro até o Paraguai, uma distância de mais de dois mil quilômetros. O episódio da Retirada da Laguna milita em favor da tese de que tal empreitada seria um falhanço.

Esses exemplos apenas confirmam um saber de senso comum, ou seja, a possível existência de uma infinidade de condicionais contrafácticos, dotados de inúmeros graus de plausibilidade. Em princípio, todos eles partilham de uma mesma propriedade, que é a indecidibilidade, mas nem todos são implausíveis. Condicionais contrafácticos são sintaticamente bem-formados e semanticamente tratáveis. Pragmaticamente, eles são onipresentes na fala cotidiana das pessoas. Eles são ubíquos ou mesmo inevitáveis em discursos científicos e nos textos elaborados pelo historiador profissional. A morte prematura de Friedrich III, do Segundo Império alemão, em 1888, leva alguns autores a especular que a 1a Grande Guerra não teria acontecido, se aquele soberano tivesse reinado até os anos 1910, pois ele era liberal e não aprovava 
conflitos armados, apesar do seu passado militar. Não há como justificar tal hipótese contrafáctica por meio de algum método efetivo que lhe prove a verdade, mas nem por isso ela deixa de ser plausível e digna de interesse. Erros de pessoas e de sociedades, com muita frequência, são percebidos apenas na perspectiva de quem olha para o que já passou. Como o historiador estuda o passado, é natural que condicionais contrafáticos ocorram no seu discurso. A matemática intuicionista tem contornos precisos, de vez que exclui hipóteses e inclui apenas o que se demonstra. O discurso histórico é bem diferente, pois está impregnado de condicionais contrafácticos. Os seus contornos não são precisos.

Nos textos aqui mencionados, Dummett não trata em pormenor de condicionais contrafáticos e da sua eventual plausibilidade, mas, ao final das suas reflexões semântico-metafísicas sobre verdade e o passado, ele se pergunta se os resultados ali obtidos seriam aplicáveis apenas a seres humanos ou, talvez, a outras entidades eventualmente dotadas de melhor equipamento cognitivo. Ele reconhece as vastas consequências que respostas a tal pergunta implicam, mas prefere deixar a cargo de seus leitores qualquer ensaio teórico a respeito do assunto. (Dummett, 2010 (2001), p. 136). Cabe notar que quem enfrenta tal tarefa, necessariamente, tem de lançar mão de condicionais contrafácticos, com a sua inevitável indecidibilidade e eventual plausibilidade.

\section{Referências}

DUMMETT, M. 2004. Truth and the Past. New York: Columbia University Press.

DUMMETT, M. 2010 (2001). Realism. In The nature and future of philosophy. New York: Columbia University Press, pp. 125-136.

HEYTING, A. 1971 (1956): Intuitionism - An Introduction. Amsterdam/London: North Holland Publishing Company, 3a ed.

KANT, I. 1968 (1783). Prolegomena zu einer jeden künftigen Metaphysik, die als Wissenschaft wird auftreten können. In Kants Werke - Akademie Textausgabe IV. Berlin: Walter de Gruyter \& Co. 